\title{
Microstructural and Mechanical Analysis of Sintered Powdered Aluminium Composites
}

\author{
Rajesh Kumar Behera $D^{1},{ }^{1}$ B. P. Samal, ${ }^{2}$ S. C. Panigrahi, ${ }^{3}$ and K. K. Muduli ${ }^{4}$ \\ ${ }^{1}$ Biju Patnaik University of Technology, Rourkela, Odisha, India \\ ${ }^{2}$ Departments of Mechanical Engineering, Orissa Engineering College, Bhubaneswar, Odisha, India \\ ${ }^{3}$ IIT Kharagpur, R. E College, Bhubaneswar, Odisha, India \\ ${ }^{4}$ Department of Mechanical Engineering, Papua New Guinea University of Technology, Lae, PMB 411, Morobe Province, \\ Papua New Guinea
}

Correspondence should be addressed to Rajesh Kumar Behera; rajesh_k_behera@yahoo.co.in

Received 18 February 2020; Accepted 23 March 2020; Published 21 April 2020

Academic Editor: Francisco Javier Fernández Fernández

Copyright (c) 2020 Rajesh Kumar Behera et al. This is an open access article distributed under the Creative Commons Attribution License, which permits unrestricted use, distribution, and reproduction in any medium, provided the original work is properly cited.

\begin{abstract}
The present material world needs strong research studies for producing varieties of composite materials which have light weight and high strength with better performances. This leads to the introduction of materials through powder metallurgy technique. The main objective is to discover an aluminium matrix composite having enhanced characteristic performances and properties beyond the currently available materials. The current study has been carried out to develop an attractive composite having high strength, light weight, easy machinability, appreciable density, and low manufacturing cost. Aluminium powders of $99.55 \%$ purity and 325 mesh sizes are mixed with alloying metals such as copper, magnesium, silicon, and silicon carbide powders in a precisely controlled quantity. The result was found with better mechanical properties, and the XRD patterns were studied in the matrix at different intensities, showing the interfacial bonding of elements gives rise to increase in strength.
\end{abstract}

\section{Introduction}

A metal matrix composite like aluminium is a better and highperformance material for industrial applications due to its acceptable properties over the presently available aluminium or its alloys [1-5]. The composite is used in the fabrication of different components in automobile sectors, electronics, aerospace applications, defense, window frames, irrigation, tubing, and petro chemical industries. The composites have unique properties over the individual metal characteristics. The researchers are focused upon the aluminium composites for their better advantages. Aluminium matrix metal composites (AMMC) will be helpful towards fabrication of different fields in engineering applications. AMMC is having elements such as copper, silicon, magnesium, and silicon carbide showing better hardness, stiffness, and tensile strength [6-8]. The interfacial relations between matrix, its reinforcement, and nature of bonding determine the structure and properties of the composites [9-11]. Powder metallurgy is a technique used for its particular characteristics such as lower sintering temperature, low cost, and uniformly homogeneous distribution of the reinforcements inside the matrix elements [12-16]. All preparations of the composite material by the powdered process can efficiently prevent the unfavorable interfacial chemical reactions at low temperatures, and the product quality is adequate with volumetric fraction of the each particle present inside the composite. The process is very easy to control. The present study described the Al-composite material preparations through the powder metallurgy route, and the metal matrix composites were studied with microstructures, XRD analysis, hardness, density, and porosity.

\section{Methodology}

In the present experiment, the powder metallurgy [17-21] method was adopted for processing of AMMCs and the 
reinforcement of metal powders were added into the matrix. The aluminium used here as a main raw material known as matrix material and was reinforced with $\mathrm{Cu}, \mathrm{Mg}, \mathrm{Si}$, and $\mathrm{SiC}$. The composite material was prepared with the process beginning with the selection of metal powders, weighing, mixing/blending, compacting, and sintering. The AMMCs was reinforced with $5 \%$ and $10 \% \mathrm{SiC}$ weight basis separately. The $\mathrm{Cu}$ powder of 325 mesh particle sizes having purity $99.77 \%$, Si powder of 325 mesh particle sizes with purity $99.87 \%, \mathrm{Mg}$ powder of 100 mesh particle sizes with purity $99.80 \%$, and $\mathrm{SiC}$ powder of 325 mesh particle size with purity 99.55\% are mixed and blended with $\mathrm{Al}$ powder of 325 mesh particle sizes with purity $99.55 \%$. The SiC particles of volume fraction $5 \%$ and $10 \%$ are mixed separately in the mixture of Al-Mg-Si-Cu [22] with the volume fractions of (91.5-0.5-0.5$2.5) \%$, respectively. The mixed/blended powder was compacted using a C-45 steel die in a digital compression testing machine with a loading rate of $0.208 \mathrm{KN} / \mathrm{sec}$ and up to $250 \mathrm{KN}$ (521.02 MPa). The green compacted specimens were removed and sintered in a muffle furnace. The sintering temperature was taken as $620^{\circ} \mathrm{C}$ and was annealed for 24 hours.

\section{Results and Discussion}

3.1. Microstructure Test. The examination of microtexture was to investigate the shape morphology, grain size, and distribution of aluminium, copper, silicon, magnesium, and especially silicon carbide particles. The microstructures of the composite were studied by utilizing inverted metallurgical microscope and SEM. The microstructures showed the uniformly distribution of silicon carbide powder particles inside the aluminium composite, and some clustering of silicon carbide aroused the reinforcement in it.

Silicon carbide distributions in the composites affected the performance of the materials directly [23]. It was observed that very few particles of silicon were heterogeneously nucleated on the particle of SiC. If the separation of $\mathrm{SiC}$ occurs between the particles due to contact with each other, it will result in the formation of porosity in the material. The microstructures of the aluminium composites are shown in Figures 1 and 2. SiC particles were considered to avoid the possibility of particle fracture and debonding under severe stress at the interface of the particulate matrix. Due to high pressure during the powder compaction process, a dense microstructure was obtained which was helpful for the improvement of material strength and heat conduction capacity. The mechanical properties were enhanced with a uniform dispersion of reinforcement particles in composites manufactured. The irregular shapes of most particles in the composite were found. The particles of the filler materials were found randomly oriented in most locations. They were incorporated and packed closely in the matrix, which improved the mechanical properties. Scanning electron images revealed that the typical microstructure had low levels of porosity and better distribution of SiC. Another important observation was the segregation and agglomeration of $\mathrm{SiC}$ at the composite interfaces. The SEM showed the presence of the dispersed phase, that is, the silicon carbide is distributed homogeneously in the aluminium matrix phase and on the surface of the composites.

3.2. XRD Test. The samples, for X-ray diffraction analysis, were prepared according to the standard sizes. Figures 3 and 4 showed an X-ray diffraction pattern (XRD) obtained for $\mathrm{Al}, \mathrm{Cu}, \mathrm{Si}, \mathrm{Mg}$, and $\mathrm{SiC}$ powders in composites to verify their quality and standard in the XRD pattern.

Composites with $5 \%$ and $10 \% \mathrm{SiC}$ reinforcements prepared by the powder metallurgy technique were subjected to $\mathrm{X}$-ray diffraction analysis for the constituents present and the results obtained. The X-ray diffraction pattern received higher intensity peaks that were clearly visible for aluminium, while many peaks are visible for SiC powder. Different constituents, such as aluminium, copper, silicon, magnesium, and $\mathrm{SiC}$, were identified after combining the experimental peaks obtained with those of the standard peaks. It was observed that the peak height increases and then decreases with the 2-theta scale [24]. It was found that the intensity was higher at 44.76 degrees (deg) on the 2-theta scale for $10 \% \mathrm{SiC}$. The higher the intensity, the greater the numbers of atoms in that position shown. Therefore, $10 \%$ of $\mathrm{SiC}$ in the composites was predicted with a better uniform distribution of the reinforcement; therefore, the mechanical properties were improved as compared with the previous research studies.

\section{Material Characterization}

4.1. Hardness Test (Rockwell). The Rockwell hardness tester (Fuel Instruments and Engineers Pvt. Ltd.) determined the composite hardness [25] by penetration of the depth made by the indenter. The hardness was measured by a steel ball indenter with spherical diamond cone shape of diameter $1 /$ $16^{\prime \prime}$ with $120^{\circ}$ angle. The hardness was measured in Rockwell scale B.

The major benefits of Rockwell hardness test was its ability to display the hardness values directly and the calculation of hardness of the composites involved, i.e., shown in Table 1 due to the application of a minor load followed by a major load.

By adding higher weight percentage of silicon carbide in AMMCs, higher BHN values in the composites were found (Figures 5 and 6), which provide better hardness to the materials. Furthermore, the research will continue to find out different machinability aspects of the sintered products.

4.2. Density and Porosity Test. The calculation of sintered density was explained by application of the law, i.e., "rule of mixture" which is shown in Tables 2 and 3. The actual density of the composites was found out to be $2.597419 \mathrm{gm} /$ $\mathrm{cm}^{3}$ and $2.688894 \mathrm{gm} / \mathrm{cm}^{3}$ in weight percentage of SiC $5 \%$ and $10 \%$, respectively, which is less than the densities calculated from the rule of mixtures. It indicated that lower the density of composites leads to light weight of materials.

The density of sample-I (SiC 5 wt \%): 


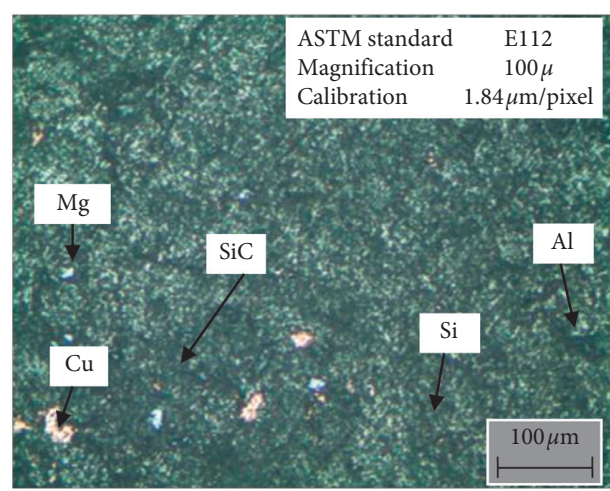

$5 \% \mathrm{SiC}$ in AMMCs

(a)

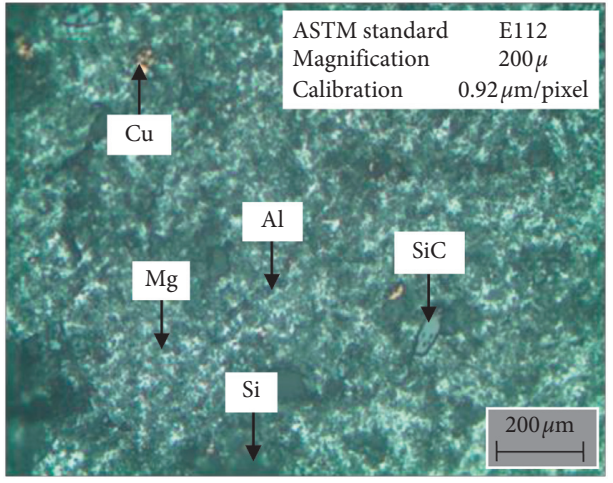

$10 \% \mathrm{SiC}$ in $\mathrm{AMMCs}$

(b)

Figure 1: Microstructure of Al-composite with $\mathrm{Cu}, \mathrm{Si}, \mathrm{Mg}$, and $\mathrm{SiC}$.

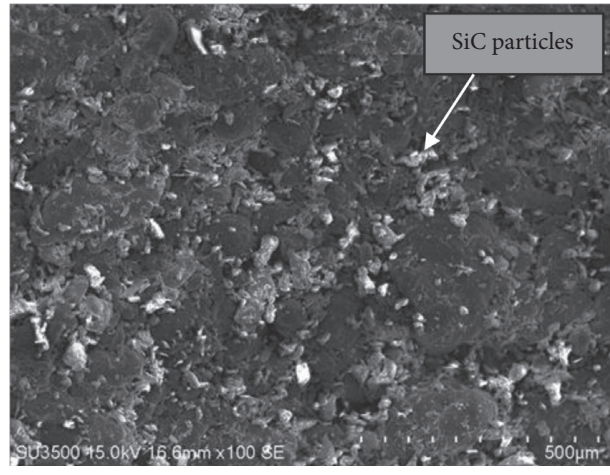

$5 \% \mathrm{SiC}$ in $\mathrm{AMMCs}$

(a)

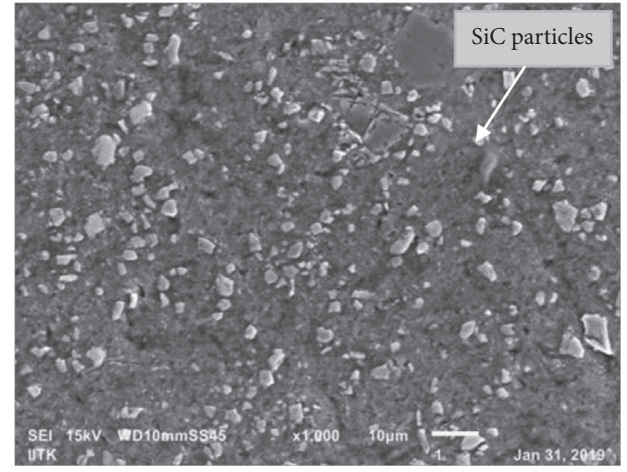

$10 \% \mathrm{SiC}$ in $\mathrm{AMMCs}$

(b)

Figure 2: Microstructure of Al-composite with $\mathrm{Cu}, \mathrm{Si}, \mathrm{Mg}$, and $\mathrm{SiC}$.

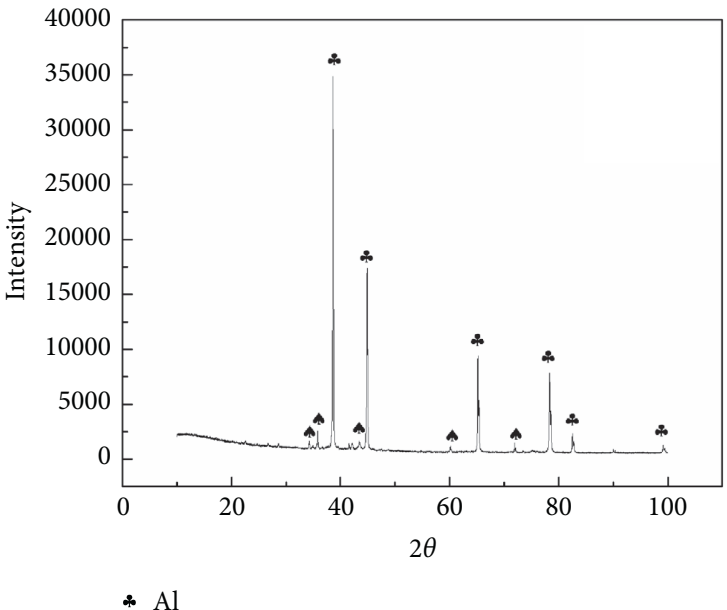

- $\mathrm{SiC}$

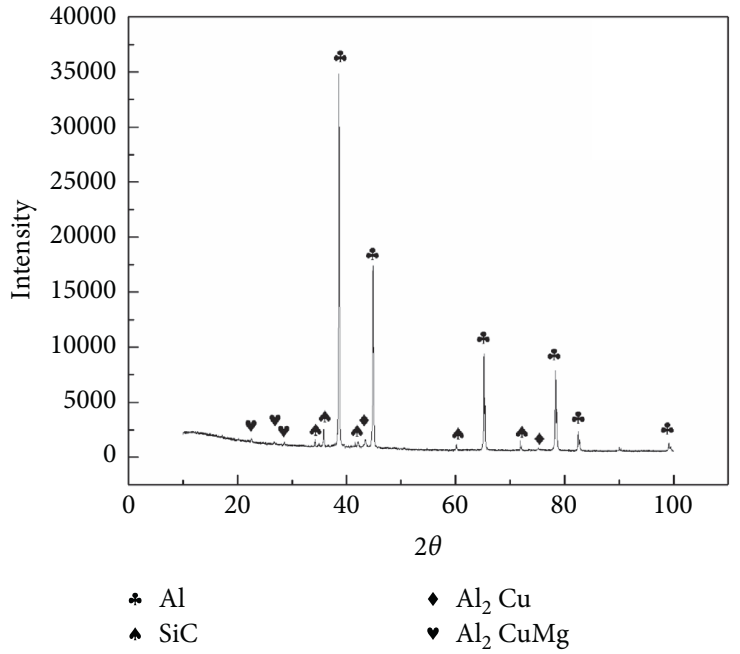

FIgURE 4: XRD pattern of $\mathrm{Al}$ composite with 10 weight $\% \mathrm{SiC}$.

FIgURE 3: XRD pattern of $\mathrm{Al}$ composite with 5 weight \% SiC. 
TABle 1: Samples of SiC reinforcement.

\begin{tabular}{lcccc}
\hline Sample nos. & $\begin{array}{c}\text { Compacted samples } \\
\text { (silicon carbide: } 5 \text { wt } \%) x=\operatorname{SiC} w t \%\end{array}$ & $\begin{array}{c}\text { Hardness test } \\
(\mathrm{HRB})\end{array}$ & $\begin{array}{c}\text { Compacted samples } \\
\text { (silicon carbide: } 10 \text { wt } \%) x=\operatorname{SiC} w t \%\end{array}$ & $\begin{array}{c}\text { Hardness test } \\
(\mathrm{HRB})\end{array}$ \\
\hline 1 & 5 & 46.0 & 10 & 52.0 \\
2 & 5 & 46.5 & 10 & 51.5 \\
3 & 5 & 46.0 & 10 & 51.5 \\
4 & 5 & 47.0 & 10 & 52.5 \\
5 & 5 & 46.5 & 10 & 51.5 \\
6 & 5 & 46.0 & 10 & 51.5 \\
7 & 5 & 46.5 & 10 & 52.0 \\
9 & 5 & 46.5 & 10 & 53.0 \\
\hline
\end{tabular}

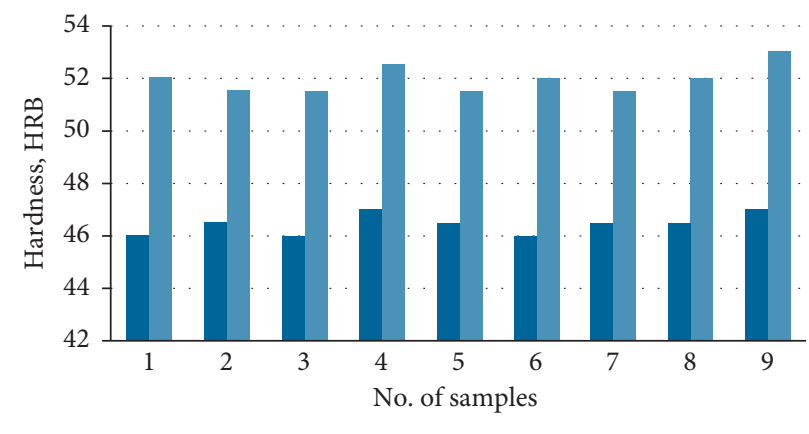

5 wt $\% \mathrm{SiC}$

10 wt $\% \mathrm{SiC}$

Figure 5: Samples vs. hardness.

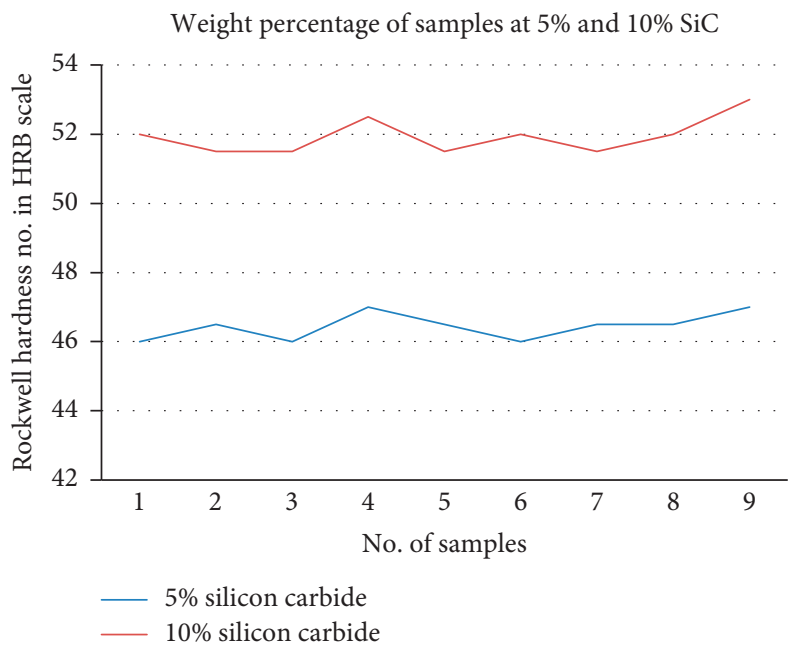

FIgure 6: Samples at different compositions of SiC.

TABLe 2: Samples of 5\% SiC reinforcement.

\begin{tabular}{lcccc}
\hline Raw metal powders & $\begin{array}{c}\text { Atomic } \\
\text { number }\end{array}$ & Density $(\rho)$ in $\mathrm{gm} / \mathrm{cm}^{3}$ & Weight percentages $(\%)$ in mixture $(x)$ & Rule of mixture $(\rho \times x)$ in gm/ $\mathrm{cm}^{3}$ \\
\hline Aluminium $(\mathrm{Al})$ & 13 & 2.70 & 91.5 & 2.4705 \\
Copper $(\mathrm{Cu})$ & 29 & 8.96 & 2.5 & 0.224 \\
Magnesium $(\mathrm{Mg})$ & 14 & 2.338 & 0.5 & 0.00869 \\
Silicon $(\mathrm{Si})$ & 12 & 3.21 & 0.5 & 0.011648 \\
Silicon carbide (SiC) & - & & 5 & 0.1605 \\
Total & & & 100 & 2.875338 \\
\hline
\end{tabular}


TABLE 3: Samples of $10 \%$ SiC reinforcement.

\begin{tabular}{|c|c|c|c|c|}
\hline Raw metal powders & $\begin{array}{l}\text { Atomic } \\
\text { number }\end{array}$ & Density $(\rho)$ in $\mathrm{gm} / \mathrm{cm}^{3}$ & Weight percentages $(\%)$ in mixture $(x)$ & Rule of mixture $(\rho \times x)$ in $\mathrm{gm} / \mathrm{cm}^{3}$ \\
\hline Aluminium (Al) & 13 & 2.70 & 86.5 & 2.3355 \\
\hline Copper $(\mathrm{Cu})$ & 29 & 8.96 & 2.5 & 0.224 \\
\hline Magnesium $(\mathrm{Mg})$ & 14 & 1.738 & 0.5 & 0.00869 \\
\hline Silicon (Si) & 12 & 2.329 & 0.5 & 0.011648 \\
\hline Silicon carbide ( $\mathrm{SiC})$ & - & 3.21 & 10 & 0.321 \\
\hline Total & & & 100 & 2.900838 \\
\hline
\end{tabular}

$$
\begin{aligned}
D & =\text { Diameter of Sample }=2.0 \mathrm{~cm}, \\
R & =\text { Radius of Sample }=1.0 \mathrm{~cm}, \\
H & =\text { Height of Sample }=7.5 \mathrm{~cm}, \\
V & =\text { Total Volume of the Sample }=\pi r^{2} H=\pi \times(1.0)^{2} \times 7.3=22.942 \mathrm{~cm}^{3}, \\
\text { So, Density of Sample }(\rho) & =\frac{\text { Mass }}{\text { Volume }}=\frac{59.59 \mathrm{gm}}{22.942 \mathrm{~cm}^{3}} \\
& =2.597419 \mathrm{gm} / \mathrm{cm}^{3} .
\end{aligned}
$$

Porosity of sample-I ( $\mathrm{SiC} 5$ wt \%):

The theoretical density of the material $=2.875338 \mathrm{gm} / \mathrm{cm}^{3}$,

Theactual/experimentaldensity of the material $=2.597419 \mathrm{gm} / \mathrm{cm}^{3}$,

$$
\text { Porosity }=\frac{\rho_{(\text {Theoretical })}-\rho_{(\text {Experimental })}}{\rho_{(\text {Theoretical })}} \times 100=\frac{2.875338-2.597419}{2.875338} \times 100=9.66 \% .
$$

The density of sample-II (SiC 10 wt \%):

$$
\begin{aligned}
& D=\text { Diameter of Sample }=2.0 \mathrm{~cm}, \\
& R=\text { Radius of Sample }=1.0 \mathrm{~cm}, \\
& H=\text { Height of Sample }=7.1 \mathrm{~cm}, \\
& V=\text { Total Volume of the Sample }=\pi r^{2} H=\pi \times(1.0)^{2} \times 7.1=22.314 \mathrm{~cm}^{3},
\end{aligned}
$$

So, Density of Sample $(\rho)=\frac{\text { Mass }}{\text { Volume }}=\frac{60.0 \mathrm{gm}}{22.314 \mathrm{~cm}^{3}}=2.688894 \mathrm{gm} / \mathrm{cm}^{3}$. 
Porosity of sample-II (SiC 10 wt \%):

$$
\begin{aligned}
\text { The theoretical density of the material } & =2.900838 \mathrm{gm} / \mathrm{cm}^{3}, \\
\text { Theactual/experimentaldensity of the material } & =2.688894 \mathrm{gm} / \mathrm{cm}^{3}, \\
\text { Porosity } & =\frac{\rho_{(\text {Theoretical })}-\rho_{(\text {Experimental })}}{\rho_{(\text {Theoretical })}} \times 100=\frac{2.900838-2.688894}{2.900838} \times 100=7.306 \%
\end{aligned}
$$

The abovementioned calculation shows that increasing of compaction pressure up to $521.02 \mathrm{MPa}$ decreased the porosity and improved the tensile properties of the composites. If the compaction pressures decrease the percentage of the porosity and the density will decrease [26]. Also, it decreases the grain size of $\alpha$-Al.

\section{Conclusions}

AMMC was prepared by metallurgical powdered technique which was a low-cost efficient method. The different mechanical properties of the aluminium composites were studied as the reinforcement particles obtained in the composites with proper ratios. Both industrial and academic researchers have displayed their interest in AMMCs because it had been observed due to following conclusions:

(1) Hardness of AMMC showed the best results when $\mathrm{SiC}$ was reinforced with 5 weight $\%$ and 10 weight $\%$ were maximum 47 and 53, respectively, in Rockwell HRB scale.

(2) Hardness increases with the increase in silicon carbide but decreases with the decreases in silicon carbide. To obtain an optimum hardness the reinforced material can be used in proper proportions.

(3) Reinforcing the matrix element with silicon carbide was found to be very negligible in pores when the mixture was done properly.

(4) Addition of $\mathrm{Cu}$ improves hardness, UTS, and reduces impact toughness of the composites.

(5) The AMMC provides the wear resistance due to addition of silicon.

(6) Wetability and light weight were found due to addition of magnesium in AMMC.

(7) Apart from the mechanical properties, the XRD pattern showed the matrix at different intensities where the interfacial bonding of the matrix directly affects the strength of the composite.

\section{Data Availability}

The data used to support the findings of the study are available from the corresponding author upon request.

\section{Conflicts of Interest}

The authors declare that they have no conflicts of interest.

\section{References}

[1] R. K. Behera, S. C. Panigrahi, B. P. Samal, and P. K. Parida, "Mechanical properties and micro-structural study of sintered aluminium metal matrix composites by $\mathrm{P} / \mathrm{M}$ technique," Journal of Modern Manufacturing Systems and Technology, vol. 3, no. 2, pp. 89-97, 2019.

[2] M. A. Ibrahim, Y. Sahin, A. Y. Auwalu Yusuf Gidado, and M. T. Said, "Mechanical properties of aluminium matrix composite including $\mathrm{SiC} / \mathrm{Al}_{2} \mathrm{O}_{3}$ by powder metallurgy-a review," Global Scientific Journals (GSJ), vol. 7, no. 3, pp. 23-38, 2019.

[3] C. Kalra, S. Tiwari, A. Sapra, S. Mahajan, and P. Gupta, "Processing and characterization of hybrid metal matrix composites," Journal of Materials and Environmental Science, vol. 9, no. 7, pp. 1979-1986, 2018.

[4] P. Garg, P. Gupta, D. Kumar, and O. Parkash, "Structural and mechanical properties of graphene reinforced aluminum matrix composites," Journal of Materials and Environmental Science, vol. 7, no. 5, pp. 1461-1473, 2016.

[5] P. Gupta, D. Kumar, M. A. Quraishi, and O. Parkash, "Influence of processing parameters on corrosion behavior of metal matrix nanocomposites," Journal of Materials and Environmental Science, vol. 7, no. 7, pp. 2505-2512, 2016.

[6] N. A. Sait and M. Ravichandran, "Synthesis and forming behavior of aluminium-based hybrid powder metallurgic composites," International Journal of Minerals, Metallurgy and Materials, vol. 21, no. 2, pp. 181-189, 2014.

[7] Z. S. Zulkoffli, "Fabrication of AL61/SiC composites by powder metallurgy process," International Journal of $\mathrm{Me}$ chanical and Materials Engineering, vol. 4, no. 2, pp. 156-159, 2009.

[8] S. Mahboob, M. H. Sajjadi, and S. A. Zebarjad, "Synthesis of $\mathrm{Al}-\mathrm{Al}_{2} \mathrm{O}_{3}$ nanocompo-site by mechanical alloying and evaluation of the effect of ball milling time on the microstructure and mechanical properties," in Proceedings of the International Conference on MEMS Nanotechnology, pp. 240-245, Kuala Lumpur, Malaysia, 2008.

[9] C. Wu, K. Ma, J. Wu et al., "Influence of particle size and spatial distribution of $\mathrm{B} 4 \mathrm{C}$ reinforcement on the microstructure and mechanical behavior of precipitation strengthened Al alloy matrix composites," Materials Science and Engineering: A, vol. 675, pp. 421-430, 2016.

[10] E. A. Diler and R. Ipek, "Main and interaction effects of matrix particle size, reinforcement particle size and volume fraction 
on wear characteristics of Al-SiCp composites using central composite design," Composites Part B: Engineering, vol. 50, pp. 371-380, 2013.

[11] E. An, A. Ghiami, and R. Ipek, "Effect of high ratio of reinforcement particle size to matrix powder size and volume fraction on microstructure, densification and tribological properties of $\mathrm{SiC}$ reinforced metal matrix composites manufactured via hot pressing method," International Journal of Refractory Metals and Hard Materials, vol. 52, pp. 183-194, 2015.

[12] M. Meignanamoorthy and M. Ravichandran, "Synthesis of metal matrix composites via powder metallurgy route: a review," Mechanics and Mechanical Engineering, vol. 22, no. 1, p. $6575,2018$.

[13] M. A. Hossaini, H. Aarabi, A. Bidi, and M. Mohammadkhani, "Construction and properties of $\mathrm{Al} / \mathrm{SiC}$ composites using nano silicon carbide by powder metallurgy technique in pure aluminum alloy," International Journal of Scientific and Engineering Research, vol. 6, no. 9, pp. 807-811, 2015.

[14] V. Jeevan, C. S. P. Rao, and N. Selvaraj, "Compaction, sintering and mechanical properties of Al-SIC composites," International Journal of Mechanical Engineering and Technology (IJMET), vol. 3, no. 3, pp. 565-573, 2012.

[15] A. K. Bodukuri, K. Eswaraiah, K. Rajendar, and V. Sampath, "Fabrication of Al-SiC-B4C metal matrix composite by powder metallurgy technique and evaluating mechanical properties," Perspectives in Science, vol. 8, pp. 428-431, 2016.

[16] C. Parswajinan, Design and Fabrication of Impact Die, Elsevier, Amsterdam, Netherlands, 2016.

[17] J. Abhilash, M. Govindaraju, S. L. N. Reddy, and K. Srikanth, "Design, analysis and fabrication of a hydraulic die ejector for a powder metallurgy component," International Journal of Mechanical Engineering and Robotics Research, vol. 4, no. 1, pp. 75-80, 2015.

[18] S. Bhasvarajappa, G. Chandramohan, A. Mahadevan, M. Thangavelu, R. Subramanian, and P. Gopalkrishnann, "Influence of sliding speed on the dry sliding wear behavior and the subsurface deformation on hybrid metal matrix," Wear, vol. 6, no. 2, pp. 1007-1012, 2007.

[19] M. S. N. K. Nijamudeen, G. Muthuarasu, G. Gokulkumar, A. Nagarjunan, and T. Pravin, "Investigation on mechanical properties of aluminium with copper and silicon carbide using powder metallurgy technique," Advances in Natural and Applied Sciences, vol. 11, no. 4, pp. 277-280, 2017.

[20] A. Xuguang, Z. Wusheng, and L. Yu, "Effect of sintering temperature on compressive strength, porosity and microstructure of $\mathrm{Al}-\mathrm{Cu}$ bearing oil bearing," Powder Metallurgy Technology, vol. 30, no. 2, pp. 108-111, 2012.

[21] H. Wenquan and C. Changzhi, "Effect of heat treatment on microstructure and properties of Al- $\mathrm{Cu}-\mathrm{Mg}$ alloy," Heat Fabrication Technology, vol. 1, pp. 157-159, 2011.

[22] G. B. Schaffer, "Powder processed aluminium alloys," $M a-$ terials Forum, vol. 28, pp. 65-74, 2004.

[23] K. K. Jangra, T. Raj, and N. Sharma, "Fabrication and development of die for powder compaction press," IOSR Journal of Mechanical and Civil Engineering, vol. 4, pp. 20-22, 2015.

[24] A. Kumar and A. S. Parihar, "A review on mechanical and tribological behaviors of stir cast copper- SiC matrix composites," International Research Journal of Engineering and Technology, vol. 3, no. 4, pp. 145-148, 2016.

[25] E. G. Kumar, M. Ahsan, K. Venkatesh, and K. S. B. S. V. S. Sastry, "Design, fabrication of powder compaction die and sintered behavior of copper matrix hybrid composite," International Journal of Engineering and technology (IRJET), vol. 5, no. 4, pp. 876-882, 2018.

[26] R. B. Bhagat, "Advanced aluminium powder metallurgy alloy and composites," ASM Hand Book, vol. 7, pp. 840-858, ASM International, Cleveland, OH, USA, 2018. 